\title{
Innovative Strategies for Developing Tuberculosis Implementation Research in Sudan
}

Ayman Ahmed Elshayeb ( $\sim$ ayman_elshayeb@yahoo.com )

Karary University https://orcid.org/0000-0002-9942-9549

Nihad Mohammed Ahmed

National Health Center

Karimeldin Mohammed Salih

University of Bisha

Osama Abu Zaid Nugoud

Elbarkal Multi Activities

Abd Allah Elnayeb Yagoub

Elbarkal Multi Activities

Abdel Karim Sabir Ali

Al-Nahrain University

Research

Keywords: Conceptual framework, Implementation, Strategies, Sudan, Tuberculosis

Posted Date: October 29th, 2020

DOl: https://doi.org/10.21203/rs.3.rs-97758/v1

License: (c) (i) This work is licensed under a Creative Commons Attribution 4.0 International License.

Read Full License 


\section{Abstract}

Introduction: Sudan, especially Eastern States are very poor areas at great risk of endemic and communicable diseases particularly tuberculosis. The reasons for the spread and transmission of this disease include medical, economical and geographical issues, besides Sudan's location in the middle of nine countries in East Africa, its boundaries were affected by free movement, high number of conflicts displaced peoples from boarders' countries, high illiteracy rates, limited financial resources and shortages in medical services.

Objectives: This project is conducted to implement a new developed system for eliminating Tuberculosis infections among eastern Sudanese populations focusing on the eradication of multidrug resistant Mycobacterium tuberculosis including novel methods for the targeted delivery of new therapeutic drugs.

Conceptual Methodology: Strategies adopted in this work are proposed to increase access includes to communicable and economic factors. Disease Survey and Laboratorial Investigation for Multi Drug Resistant bacterial strains confirmation. Medical Assessment of TB Patients to facilitate improved efficiencies through metric measurement and enable patients' relationship management. Established a national level policy of treatment, vaccination and prevention. Administering regular evaluation of the disease situation and control.

Results: Implementation outcomes includes the conceptual framework for this project were informed by a combination of the general program logic model, the health system framework of the World Health Organization, WHO, the pillars of the Sudan health agenda, and the framework of the Strategic Elimination Plan. It is assumed that the reduction of TB burden at the national level (long-term output or impact) is preceded by improved case-finding and case-holding practices (short-term output). Impact outcome of the project is derived from the observation that tuberculosis is much more common at the boarders than center of Sudan where no adequate clinical services are available. It is conceivable that, although outbreaks may occur periodically, the control of disease might be easier to overcome than direct medication.

Conclusion: A major success of the project accomplishment, is the stimulation of the implementation strategy development for elimination and eradication of Tuberculosis in Sudan with a view to bring diagnostic and surveillance issues much higher up according to the implementation research agenda especially for those areas explored with similar national and international research projects, reports and technical initiatives.

\section{Contributions To The Literature:}

- Africa -with its all conflicts- at great risk of endemic, pan-endemic and epidemic of tuberculosis spread and outbreaks

- Reasons for spread and transmission of these diseases among poor communities are affected by free movement, high number of war displaced peoples beside other demographical issues. 
- Poor health systems coverage in Africa make it very important to interevent with emerging Implementation Research projects taking into account the proportion of clinical cases with underestimating the burden of tuberculosis.

- Utilizing data on actual burden of tuberculosis is crucial for health authorities to design control programs for developing public health strategies such as surveillance, early warning and quick response system for spread and outbreaks, all can be defined as Implementation Research Conceptual Framework.

\section{Introduction:}

Globally, tuberculosis remains one of the top 10 causes of death worldwide. Millions of people continue to fall sick from TB each year(1-3). The huge biodiversity in Sudan, has a great bacterial record showed variable characteristics of infections and antibiotics susceptibility, this gives an excellent opportunity to find the effective intervention system(4). This study emphasizes the implementation systems that control, analyze and characterize TB treatment. In Sudan, especially the Eastern States, there are many areas at great risk of endemic, poverty and communicable diseases particularly tuberculosis (5-7). The reasons for the spread and transmission of the disease in Sudan are attributed to medical, economical and geographical location of the country which is bounded by nine Eastern African countries; free movement, high number of Conflicts displaced peoples from boarders' countries, high illiteracy rates, limited financial resources(8). The human host serves as the only natural reservoir for Mycobacterium tuberculosis of majority of tuberculosis but natural disasters such as aridity and geographical inaccessibility of some areas especially during the dry season can affect the circulation of tuberculosis in the Sudan(9). Poor health system coverage makes it very important to conduct a population-based prevalence survey taking in to account the proportion of clinical cases which is always very few as such as a tip of iceberg underestimating the burden of the disease because most of the cases are asymptomatic infections(10-14). b Urban areas have, in general, greater health provider diversity, are socioeconomically and culturally more diverse, and operate under different governmental structures. Furthermore, the transmission pattern and intensity are often different from rural areas. Many of these factors influence health seeking behaviour and perceptions about the disease, as well as case-definition and the epidemiology of tuberculosis, and, in general, methods, points and approaches for potential intervention. Moreover, the symptomatic cases are not adequately reported, so data on the actual burden of the disease is crucial for the public health authorities to design control programs(15-17). The prevalence of risk factors of tuberculosis can be used to ascertain the vulnerable groups and develop public health strategies namely adequate surveillance system and early warning and response body to guard particularly against multi-drug resistant tuberculosis. Principally, the risk of anti-drugs resistant disease is very high; this increases the need to find new low-cost drugs(18-20). One of the more interesting aspects of the present study into new implementation systems may in fact be the sequencing of their outcomes. The most important outcome is the change into how studying the treatment, vaccination and prevention is approached. It is also quite likely that even if the initial research is relatively not costly, the results may have great benefits in poor communities. 


\section{General Objective:}

The general objective of this project is to implement a new developed system for eliminating Tuberculosis infections among Sudanese focusing on the eradication of multidrug resistant Mycobacterium tuberculosis using novel methods for the targeted delivery of new therapeutic drugs.

\section{Specific objectives are to:}

1. Manage clinical and diagnosis process inside the endemic area.

2. Control drug delivery to patients through direct channels.

3. Utilize stakeholders outsourcing, networking, and connections for serving patients.

4. Management of surveillance and data collection.

5. Assess conceptual, outcomes and evaluation systems.

\section{Methodology:}

\section{Study area/setting}

Sudan $\left(1,886,068 \mathrm{~km}^{2}\right)$, has 18 states after separation of South Sudan in 2011. The geostatistical and the socioeconomic model will be an inclusive framework that takes various aspects of the study area, such as economic status, social and the geospatial distribution of TB into consideration. Climate change may have effects in the spread of TB, where the environment can be seen as a biosocial determinant of the diseases, it provides a direct space in which infection can take place, predominantly through increased exposure.

\section{Sample Size:}

Sudan population is 32 million according to 2008 census excluding the separated South Sudan. The prevalence of Tuberculosis is very high especially among Eastern states' populations; namely Kassala $(2,519,071)$, Al-Gedarif $(2,208,385)$ and The Red Sea $(1,482,053)$ respectively. These populations were chosen for a survey and/or experiment using World Health Organization recommended Sample Size Calculator and Sampling Spreadsheet (The STEPS) that can assist in first determining the size of sample and then in drawing a sample from sampling frame (https://www.who.int/ncds/surveillance/steps/resources/sampling/en/). This will construct a 95\% confidence interval with a margin of error of about $\pm 4.4 \%$ (for large populations).

\section{Medical intervention for tuberculosis infections:}




\section{Onsite clinical testing and investigations}

Tuberculin skin test (TST) and/or interferon-gamma release assay (IGRA) were used to test for LTBI, both tests measure immune sensitization (type IV or delayed-type hypersensitivity) to mycobacterial protein antigens that occurs following infection by M. tuberculosis. Antibiotic susceptibility testing to isoniazid or rifampicin will be done by using CLSI guidelines and the second-line drugs considered are those listed in the WHO Guidelines for the Management of Drug Resistant Tuberculosis(21).

\section{Medical Assessment of Tuberculosis Patients:}

1-Patient Registration: of both healthy and sick patients.

2-Appointment Management: with routine reminders to notify patients about appointments and delays.

3- Reports and Dashboards: To facilitate improved efficiencies through metric measurement. 4-Computer software: To enable patients' relationship management especially for chronic patients who visit the clinics more often.

\section{Inclusion Criteria:}

The inclusion criteria included the following: (a) Tuberculosis diagnosis (b) tuberculosis treatment fully conducted at field site during infection pandemic and (c) being African citizens or residents.

\section{Exclusion Criteria:}

The exclusion criteria included the following: (a) death within the first 15 days of treatment, (b) treatment default during the first 30 days after treatment initiation, (c) change of Tuberculosis diagnosis during treatment, (d) transfer to other health unit, or (e) unknown treatment outcome. The project also will provide information on socio-demographic variables, presence of comorbidities, tuberculosis features and treatment, which we included as covariates.

\section{Management of Mobile Emergency health intervention:}

Using well equipped mobile clinics, labs and pharmacies for emergency intervention is essential especially in those areas who lack for regular health facilities, outreach clinic mobiles aim to provide primary and emergency health care services for poor communities.

Data Collection methods, instruments used, measurements:

\section{Networking and media and communication:}

Data that has been collected and analyzed must be passed on to decision makers, the staff involved, and partners. This communication aspect is an essential component of a surveillance system and includes: 


\section{Surveillance data collection}

Public health surveillance in points of care for communities/migrants operates inside camps with daily collection of epidemiological data for selected syndromes/health conditions that are important from a public health point of view. Data recorded refer to consultations for each syndrome/condition under surveillance in primary health care facilities in community/migrant reception centers. Data are sent daily to the Department of Surveillance and Intervention of communities by doctors, nurses and other health professionals from services and NGOs staffing primary care facilities.

\section{Data quality assurance methods, data management and analysis plans:}

All official statistical activities shall be conducted in accordance with a Data Quality Framework that shall be developed by the National Centre for Statistics and Information in consultation with other government units that conduct official statistical activities. Once developed, the Data Quality Framework will be promulgated by Regulation/Government Decree (need to specify the legal process involved)"

\section{Developing the national level policy of treatment, vaccination and prevention:}

1-Developing drug delivery to lower levels and the cost of supervision of the communities.

2- Community based TB care developed together with implementing partners (Conduct situational analysis, establish partnership \& coordination mechanism and Developing surveys).

3- Conducting a needs analysis, administering surveys, conducting interviews and developing curriculum.

\section{Administering regular evaluation of the disease situation}

1- Organize community base and multidisciplinary teams.

2- Regular Survey and Monitoring

3- Quarterly Review Meeting.

4-Dissemination of training materials.

5-Infection Control.

\section{Strategies to increase community access:}


1- Education: Patient consulting, social marketing,

2-Management: Financial management, business management.

3-Regulation: Standards development, task-shifting.

4-Economic: Insurance plans, pooled procurement.

\section{Major workplan and Budget}

The work plan identified tasks, time and period of the activity took place and executive responsible person as scheduled in appendix (B). An outline of the financial costs involved in implementing the proposed study and any other essential resources was declared in appendix (C).

\section{Results And Outcomes:}

\section{The prevalence of tuberculosis among population}

The disease total estimations in Sudan were 200,000 cases with 200 new infections annually include 1.9\% Multi-Drug-Resistant Mycobacterium tuberculosis and 20.0\% of them were previous treated patients (Fig. 1). Using World Health Organization Sample Size Calculator, the final sample size $=0.015$ for all Eastern States (Appendix A 1,2).

\section{Management of mobile health intervention:}

\section{Management of mobile clinic}

Clinic Management Systems to give complete end to end solutions to clinics that are looking for administrative support along with Record Management. The Clinic Management System is focused on bringing in efficiencies into the mobile clinics by streamlining Appointment management, Registration and follow up along with maintaining electronic records for all TB patients. The system was ensuring collection of appropriate data to be able to present dashboards to the key users with a focus on improving clinical and operational efficiencies and reducing costs.

\section{B) Management of mobile laboratory:}

Simple laboratory tests such as microscopy, ICTs blood tests, hemoglobin estimation and urine examination are carried out at camps by regular moving of laboratory with its technicians. The clinics received referrals from the laboratory technicians for the management of medical and surgical emergencies and making etiological diagnosis quick and correct. 


\section{C) Management of mobile Pharmacy:}

Quick delivery of health services including treatment and vaccinations attuned to the needs of patients in different area. Monitoring of patients' health and their outcomes: An important benefit of the project drug delivery is derived from observations that tuberculosis patients at the boarders are suffering from lack of medical services than others.

\section{Management of communication network}

include coordinate with others. Interagency and interpectoral coordination should be established to ensure comprehensive care for community.

Conduct orientation meetings with community leaders; include representatives of social and community services, protection, the police or legal justice system, and security. Depending on the services available in the particular setting, others may need to be included. As a multi-sectoral team, establish referral networks, communication systems, coordination mechanisms, and follow-up strategies as shown in (Table-1).

Table 1

Formal and Informal Communication Channels Matrix in a typical Sudanese community

\begin{tabular}{|ll|}
\hline Communication channel & Perceived Effectiveness \\
\hline Announcements at mosque by Sheik & Very effective \\
\hline Public address system by partners & Very effective \\
\hline Community leaders meeting then information dissemination & Very effective \\
\hline Community meeting & Very effective \\
\hline Community radio & Effective \\
\hline Role Plays & Effective \\
\hline Mobile phones & Effective \\
\hline Health education at facility level & Effective \\
\hline Printed materials & Less effective \\
\hline
\end{tabular}

\section{Implementation of service delivery plan}

Implement solutions determined in the Improve stage. Comprehend both technical as well as any business process related changes. Implement a comprehensive 'Change Management' plan to ensure that all stakeholders are appropriately trained. 


\section{Data Control Measurement}

Verify at periodic intervals that the data is consistent with the business goals and the data rules specified in the Definition Step. Communicate the Data Quality metrics and current status to all stakeholders on a regular basis to ensure that Data Quality discipline is maintained on an ongoing basis across the organization as declared in (Table-2).

Table 2

Data Quality \& Assurance for implementation of service delivery plan

\begin{tabular}{|c|c|}
\hline Activity & Responsible Organization/ Person \\
\hline Conduct situational analysis & Implementing Partners \\
\hline \multirow{2}{*}{$\begin{array}{l}\text { Establish partnership \& coordination } \\
\text { mechanism }\end{array}$} & Township health committee \& Implementing \\
\hline & Partners and/all stakeholders \\
\hline \multicolumn{2}{|l|}{ Capacity building } \\
\hline \multirow[t]{2}{*}{ Dissemination of training materials } & National Tuberculosis Program at \\
\hline & Region/State level \\
\hline Training & $\begin{array}{l}\text { NGOs, Township health staff with technical support from } \\
\text { National Tuberculosis Program }\end{array}$ \\
\hline Infection Control & All health workers \\
\hline \multirow{2}{*}{$\begin{array}{l}\text { Advocacy, Communication and } \\
\text { Social }\end{array}$} & Key stakeholders, National Tuberculosis \\
\hline & Program and Implementing Partners \\
\hline \multicolumn{2}{|l|}{ Supervision } \\
\hline $\begin{array}{l}\text { Organize community base and } \\
\text { multidisciplinary teams }\end{array}$ & Led by Implementing Partners and local authorities \\
\hline \multirow[t]{2}{*}{ Regular Survey and Monitoring } & Joint supervision, National Tuberculosis \\
\hline & Program, and Implementing Partners \\
\hline Quarterly Review Meeting & $\begin{array}{l}\text { TMO, BHS, TB Coordinators, Volunteers, focal from IPs and } \\
\text { local authorities }\end{array}$ \\
\hline
\end{tabular}

* Data Quality is not a onetime project but a continuous process and requires the entire organization to be data-driven and data-focused. With appropriate focus from the top, Data Quality Management can reap rich dividends to organizations.

\section{Implementation Research Outcomes}


The conceptual framework for this project was informed by a combination of the general program logic model, the health system framework of the World Health Organization, the pillars of the Sudan health agenda, and the framework of the Strategic Elimination Plan. It is posited that the reduction of TB burden at the national level (long-term output or impact) is preceded by improved case-finding and case-holding practices (short-term output).

\section{Medical intervention and quick response:}

These, in turn, require the following inputs and activities: (i) delivery of health services that are consistent with accepted standards, but are also attuned to the needs of the local population; (ii) availability of human, material and financial resources to support program implementation; (iii) evidence-informed decision making; (iv) exercise of administrative oversight, and presence of support from policy-makers and local stakeholders; and (v) effective partnerships that harness contribution from the other government agencies, private sector and civil society.

\section{Acceptability}

Perception of local policy-makers and decision-makers on their agreement to the TB prevention and control program as cascaded by the national government (and development partners, as applicable).

\section{Appropriateness}

Perception of local policy-makers and decision-makers on the relevance to their local context of the TB prevention and control program as cascaded by the national government (and development partners, as applicable).

\section{Fidelity}

The consistency and quality of the intervention's implementation was implemented as intended due to major plan and conceptual framework (Figures-2, 3)

\section{Feasibility}

Perception of local policy-makers and decision-makers on the practicality of implementing the TB prevention and control program as cascaded by the national government (and development partners, as applicable). For purposes of the implementation research, the acceptability, appropriateness and feasibility of the package of interventions for TB prevention and control as provided by the national government from the local policy-makers shall be considered as among these potential driving or restraining forces. 


\section{Implementation research outcomes}

\section{Socio-(economic, politics, cultural) impact outcome}

An important benefit of the project is derived from the observation that tuberculosis is much more common in boarders than center of Sudan where no clinical services. It is conceivable that, although outbreaks may occur periodically, the control of disease might be easier to overcome than direct medication.

\section{Direct health impact outcome}

Changing the regular health policies and the prevention approach have great benefits in poor communities. Another obvious outcome is the increase of patient's outreach, treatment and vaccination from $25 \%$ up to $75 \%$ in Dordabe locality Eastern Sudan

\section{Beneficial impact outcome}

Developing implementation strategy for elimination and eradication of Tuberculosis has stimulated funds from national and (expected international) relevant organizations and academia.

\section{Future Prospects}

- Development of future management systems could offer powerful tools for disease management within wider strategies of control

- The Project is an attempted a grand challenge to identify future risks from tuberculosis across Sudan and neighborhood.

- Implementation of a new research study and technology that might reduce such risks.

- Development of alternative therapeutics technology platform against MDR tuberculosis using novel methods for the targeted delivery of Bacteriophage Therapy

\section{Discussion:}

Tuberculosis is well-considered as an endemic and economic related disease in many countries as a result of poverty $(22,23)$. Many health systems in the Globe depend on clinical, official and governmental efforts without considering other implementation research settings against tuberculosis defeating(24). Although the recent health managerial policies of disease control were successful in the treatment of the disease but they failed in eradication (particularly the MDR tuberculosis) due to the lack of effective implementation research studies and trials(25-27). The present study showed the impact of a new empirical, managerial and integrated system for tuberculosis treatment in Sudan using innovative strategies of implementation research and how it is suitable for other countries who have similar conditions of disease epidemiologic. The risk of tuberculosis outbreaks among people fleeing hardship for poor, war's victims and refugees in Sudan is heightened by the description of the local health response 
to outbreak of tuberculosis among all those patients (28). Conflict and war have long been recognized as determinants of infectious disease risk, re-emergence of epidemic tuberculosis and also has coincided with extensive civil conflict in affected regions(29). The needs of Implementation Research are very important for the critical health situation in Eastern Sudan, where the population has been suffering for long time from the endemic TB, beside poverty and long distant has stimulate the need of mobile comboclinic for patients' outreach. This emergency facility has been used in many countries as stated by (3033). The success of such implemented research is obviously seen in the reduction of the disease among the selected populations, this is in agreement with(34) who outlined the implementation challenges around the diagnosis and treatment of TB and described how current TB preventive therapy activities have been shaped and managed. The triangular conceptual framework (World Health Organization, local health authorities, and our innovative Strategic Plan) was implemented as an urgent responded action to eliminate the disease spreading (Figure - 2)(35). The conceptual framework's inner settings (health services) and outer settings (the financial and sociopolitical environment of local health services) were combined to obtain the highest level of the program perfection(36). This novel framework highlighted the morbidity, disability and heightened mortality that persist after successful treatment completion, in order to appreciate the importance of TB preventive therapy in the overall context of ending the MDR-TB epidemic and ensuring healthy lives(37). The Medical intervention combination (laboratory investigations, patient's assessment, drug delivery and vaccination) all together trigged an immediate quick response to tuberculosis emerging by implementing new strategies based on acceptability of a functional public network composed of specialist, stakeholders, community leaders who have been informed and connected via different means of media including social media(Table-1)this was previously stated by $(38,39)$. The appropriateness of the program was simplified to local communities by intensive training, lectures and meetings for better understanding, assessment and control of collected data (Table2). A well-prepared budget for project feasibility was included in the two years plan which has been found it is the minimum period to implement such a project (40). The fidelity transition from input to impact is influenced by the presence of antecedent factors (i.e., elements that the program starts out with, usually forming part of the local milieu) and the emergence of mediating factors (i.e., influences that arise as the program unfolds) (35). Borrowing from force field analysis, inputs, antecedent factors and mediating factors can be classified into two: driving forces (i.e., facilitators, or factors, which, when increased, support attainment of the desired output), and restraining forces (i. e., barriers, or factors, which, when increased, support the status quo or detract from attainment of the desired results)(41-43). It is noteworthy to mention that a restraining force can be the absence of a particular input or contextual factor(44). Our implementation research outcomes were clearly divided into direct and indirect categories, this agreed (45) where the direct health impacted outcome was attenuated by changing regular health policies and prevention approached that have great benefits for poor communities resulted in their life hood enhancement as indirect outcomes(46). One major outcome is the increasing of patient's outreach, treatment and vaccination from $25 \%$ up to $75 \%$ obviously seen in Dordabe locality Eastern Sudan (Figure3 ). The indirect outcomes were assembled in one category contains (economic, politics, cultural outcomes) which highlighted the importance of such approaches that have been credited by stakeholders with leading to greater acceptance of the need to integrate natural and social sciences in disease-related 
work, where a barrel research projects at the economics explicitly should be continued to explore this link $(41,42)$. A number of the experts that worked on the Project have to continue to research the issues raised during the Project and help lead initiatives and organizations that work on associated areas. The study further assesses some of the implementation challenges of TB preventive therapy and propose how activities can be improved and enhanced through research and innovative strategies for future prospects and increasement of beneficial impact outcomes obtained by developing implementation research for elimination and eradication of Tuberculosis, this in agreement with (47),where the backbone of the project has remained as an enduring point of reference for the 'One Health' Agenda. The project also emphasis on the importance of detecting disease and promoting a joined up One Health approach to be reflected in the creation of some new collaborative networks regionally and globally (48). The establishments of an Inter-departmental and coordination group for high containment facilities is highly needed to develop and have global approach to the procurement of evidence for tuberculosis as stated by(49). The Project also can be credited with the importance that issues concerning the emergence of tuberculosis in Africa should be seen as a global public good, therefore, the extension of the project into Africa was a novel and previously unexplored idea, which in turn will lead to the support and creation of African Centre for Tuberculosis Surveillance directed by African Project team members $(50,51)$.

\section{Conclusion:}

A major success of the project accomplishment, is the stimulation of the implementation strategy development for elimination and eradication of Tuberculosis in Sudan with a view to bring diagnostic and surveillance issues much higher up according to the research agenda especially for those areas explored with similar national and international research projects, reports and technical initiatives. The Project also highlighted the importance of economic, social and communicable approaches that have been credited by stakeholders with leading to greater acceptance of the need to integrate natural and social sciences in disease - related work. The annual and Mid-term review showed that further and- in some casesimpressive progress which has been made in affecting change and influencing policy. The project successfully stimulated the development of the implementation strategy for elimination and eradication of Tuberculosis in Sudan with a view to bring diagnostic and surveillance issues much higher up than the research agenda expectations, with the area explored in similar national and international research projects, reports and technical initiatives.

\section{Declarations}

\section{- Ethics approval and consent to participate:}

Can be found as separate attachments

1- Ethical approval in English was issued from Elbarkal research committee

2- Consent to participate in Arabic was issued for patients' participation

Page $13 / 20$ 


\section{- Consent for publication:}

An attached license agreement has been signed.

\section{- Availability of data and materials:}

All data and materials are available upon request

\section{- Competing interests:}

Authors have no competing interests

\section{- Funding:}

This work was supported by Elbarkal Multi Activities, Dept. Research \& Consultancy [Local fund sources No; 4] for the initiated phase of the project in the selected Dordabe area. To complete al phases the project is applying for international funds.

\section{- Authors' contributions:}

A. A. E. (Principle Investigator), manuscript preparation, coordinated and carried out the study, O.A. N. (Social and Economic Evaluator) and A.A. E. Y. (Director) planed and designed the strategies of the project, performed the statistical analysis and participated in drafting the paper. N. M. A. carried out laboratory investigations, literature review and data analysis. K. M. S. designed patient assessment protocols, medical workshops and manuscript methodology arrangement, A. S. A. designed stakeholders training, locals' lectures, public orientations, paper's results interpretation and validation. All authors contribute manuscript preparation, read and approved the final draft.

\section{- Acknowledgements:}

We would like to acknowledge with gratitude the assistance received from Dr. Mubarak Karsany (Karary University), Federal Ministry of Health, (and their cooperative laboratories staff. The government, the local authorities, tribes' leaders and population of Kassala, El- Gedarif and Red Sea States.

\section{- Authors' information (optional)}

1. Mr. Ayman Ahmed Elshayeb: MSc, PhD, Microbiologist @ Research and Development, Elbarkal Multi Activities, Khartoum - Sudan. ayman_elshayeb@yahoo.com

2. Dr. Nihad Mohammed Ahmed: PhD; Microbiologist @ Dept. Tuberculosis, Tropical Medical Research Institute, National Health Centre, Ministry of Health, Khartoum - Sudan. nihadbio@yahoo.com

3. Prof. Karimeldin Mohammed Salih: PhD, MD; Paediatrics and Medical Education @ Departments of paediatrics and Medical Education, College of Medicine, University of Bisha, Saudi Arabia. 
karimeldin_salih@hotmail.com

4. Dr. Osama Abu Zaid Nugoud: PhD, Post Doc; Social Scientist @ Dept. Projects and Research Evaluation, Elbarkal Multi Activities, Khartoum - Sudan. me.gogetter@gmail.com

5. Mr. Abd Allah Elnayeb Yagoub: General Director. MBA; Business Development @ Dept. Projects and Research Administration, Elbarkal Multi Activities, Khartoum - Sudan. elnaip@yahoo.com

6. Prof. Abdel Karim Sabir Ali: PhD; Environmentalist @ Dean College, Faculty of Science and Technology, Al Neelain University, Khartoum - Sudan. aksabirali@gmail.com

\section{References}

1. Rens NE, UyI-de Groot CA, Goldhaber-Fiebert JD, Croda J, Andrews JR. Cost-Effectiveness of a Pharmacogenomic Test for Stratified Isoniazid Dosing in Treatment of Active Tuberculosis. Clin Infect Dis. 2020.

2. Nour-Neamatollahi A, Siadat SD, Yari S, Tasbiti AH, Ebrahimzadeh N, Vaziri F, et al. A new diagnostic tool for rapid and accurate detection of Mycobacterium tuberculosis. Saudi J Biol Sci. 2018;25(3):418-25.

3. Botha GHR, Theron G, Warren RM, Klopper M, Dheda K, van Helden PD, et al. Detection of tuberculosis by automatic cough sound analysis. Physiol Meas. 2018;39(4):045005.

4. Kiwou MK, Lanetti R, Sladeckova V, Kalavska A, Benca GJ, Sokolova J, et al. Tropical neuroinfections in south sudanese rural hospitals - analysis of 8,709 patients. Neuro Endocrinol Lett. 2013;34(Suppl 1):24-7.

5. Ahmed R, Robinson R, Mortimer K. The epidemiology of noncommunicable respiratory disease in sub-Saharan Africa, the Middle East, and North Africa. Malawi Med J. 2017;29(2):203-11.

6. Elmadhoun WM, Noor SK, Bushara SO, Ahmed EO, Mustafa H, Sulaiman AA, et al. Epidemiology of tuberculosis and evaluation of treatment outcomes in the national tuberculosis control programme, River Nile state, Sudan, 2011-2013. East Mediterr Health J. 2016;22(2):95-102.

7. el-Safi SH, Hamid N, Omer A, Abdel-Haleem A, Hammad A, Kareem HG, et al. Infection rates with Leishmania donovani and Mycobacterium tuberculosis in a village in eastern Sudan. Trop Med Int Health. 2004;9(12):1305-11.

8. Buliva E, Elhakim M, Tran Minh NN, Elkholy A, Mala P, Abubakar A, et al. Emerging and Reemerging Diseases in the World Health Organization (WHO) Eastern Mediterranean Region-Progress, Challenges, and WHO Initiatives. Front Public Health. 2017;5:276.

9. May JP, Joseph P, Pape JW, Binswanger IA. Health care for prisoners in Haiti. Ann Intern Med. 2010;153(6):407-10.

10. Querri A, Ohkado A, Kawatsu L, Remonte MA, Medina A, Garfin AMC. The challenges of the Philippines' social health insurance programme in the era of Universal Health Coverage. Public Health Action. 2018;8(4):175-80. 
11. Ranabhat CL, Kim CB, Singh A, Acharya D, Pathak K, Sharma B, et al. Challenges and opportunities towards the road of universal health coverage (UHC) in Nepal: a systematic review. Arch Public Health. 2019;77:5.

12. de Souza RA, Nery JS, Rasella D, Guimaraes Pereira RA, Barreto ML, Rodrigues L, et al. Family health and conditional cash transfer in Brazil and its effect on tuberculosis mortality. Int J Tuberc Lung Dis. 2018;22(11):1300-6.

13. Verguet S, Jamison DT. Health Policy Analysis: Applications of Extended Cost-Effectiveness Analysis Methodology in Disease Control Priorities, Third Edition. In: rd, Jamison DT, Gelband H, Horton S, Jha P, Laxminarayan R, et al., editors. Disease Control Priorities: Improving Health and Reducing Poverty. Washington (DC)2017.

14. Durovni B, Saraceni V, Puppin MS, Tassinari W, Cruz OG, Cavalcante S, et al. The impact of the Brazilian Family Health Strategy and the conditional cash transfer on tuberculosis treatment outcomes in Rio de Janeiro: an individual-level analysis of secondary data. J Public Health (Oxf). 2018;40(3):e359-e66.

15. Ragonnet R, Underwood F, Doan T, Rafai E, Trauer J, McBryde E. Strategic Planning for Tuberculosis Control in the Republic of Fiji. Trop Med Infect Dis. 2019;4(2).

16. Png ME, Yoong J, Ong CWM, Fisher D, Bagdasarian N. A screening strategy for latent tuberculosis in healthcare workers: Cost-effectiveness and budget impact of universal versus targeted screening. Infect Control Hosp Epidemiol. 2019;40(3):341-9.

17. Diaw MM, Ndiaye M, Riccardi N, Ungaro R, Alagna R, Cirillo DM, et al. Implementing TB control in a rural, resource-limited setting: the stop-TB Italia project in Senegal. Multidiscip Respir Med. 2018;13:41.

18. Elduma AH, Mansournia MA, Foroushani AR, Ali HMH, Elegail AMA, Elsony A, et al. Assessment of the risk factors associated with multidrug-resistant tuberculosis in Sudan: a case-control study. Epidemiol Health. 2019;41:e2019014.

19. Bayoumi RR, van der Poel S, El Samani EZ, Boivin J. An evaluation of comprehensiveness, feasibility and acceptability of a fertility awareness educational tool. Reprod Biomed Soc Online. 2018;6:10-21.

20. Sobe Jermano Boyong C, Kankya C, James M, Munyeme M, Jubara AS, Ndoboli D, et al. Dynamics of tuberculosis in Wau, South Sudan during a period of armed conflict. J Clin Tuberc Other Mycobact Dis. 2018;12:54-65.

21. Falzon D, Jaramillo E, Schunemann HJ, Arentz M, Bauer M, Bayona J, et al. WHO guidelines for the programmatic management of drug-resistant tuberculosis: 2011 update. Eur Respir J. 2011;38(3):516-28.

22. Ploubidis GB, Palmer MJ, Blackmore C, Lim TA, Manissero D, Sandgren A, et al. Social determinants of tuberculosis in Europe: a prospective ecological study. Eur Respir J. 2012;40(4):925-30.

23. Weiss MG, Somma D, Karim F, Abouihia A, Auer C, Kemp J, et al. Cultural epidemiology of TB with reference to gender in Bangladesh, India and Malawi. Int J Tuberc Lung Dis. 2008;12(7):837-47. 
24. Lin HH, Langley I, Mwenda R, Doulla B, Egwaga S, Millington KA, et al. A modelling framework to support the selection and implementation of new tuberculosis diagnostic tools. Int J Tuberc Lung Dis. 2011;15(8):996-1004.

25. Raftery P, Kodmon C, van der Werf MJ, Nikolayevskyy V. European Union training programme for tuberculosis laboratory experts: design, contribution and future direction. BMC Health Serv Res. 2020;20(1):413.

26. Mekebeb MB, Von Pressentin K, Jenkins LS. Institutional tuberculosis infection control in a rural subdistrict in South Africa: A quality improvement study. Afr J Prim Health Care Fam Med. 2019;11(1):e1-e8.

27. Verkuijl S, Middelkoop K. Protecting Our Front-liners: Occupational Tuberculosis Prevention Through Infection Control Strategies. Clin Infect Dis. 2016;62 Suppl 3:S231-7.

28. Walker TM, Merker M, Knoblauch AM, Helbling P, Schoch OD, van der Werf MJ, et al. A cluster of multidrug-resistant Mycobacterium tuberculosis among patients arriving in Europe from the Horn of Africa: a molecular epidemiological study. Lancet Infect Dis. 2018;18(4):431-40.

29. Berrang Ford L. Civil conflict and sleeping sickness in Africa in general and Uganda in particular. Confl Health. 2007;1:6.

30. Lee JH, Han CD, Cho SN, Yang IH, Lee WS, Baek SH, et al. How Long Does Antimycobacterial Antibiotic-loaded Bone Cement Have In Vitro Activity for Musculoskeletal Tuberculosis? Clin Orthop Relat Res. 2017;475(11):2795-804.

31. Hepple P, Novoa-Cain J, Cheruiyot C, Richter E, Ritmeijer K. Implementation of liquid culture for tuberculosis diagnosis in a remote setting: lessons learned. Int J Tuberc Lung Dis. 2011;15(3):405-7.

32. Tiong AC, Patel MS, Gardiner J, Ryan R, Linton KS, Walker KA, et al. Health issues in newly arrived African refugees attending general practice clinics in Melbourne. Med J Aust. 2006;185(11-12):602-6.

33. Iribarren SJ, Rodriguez Y, Lin L, Chirico C, Discacciati V, Schnall R, et al. Converting and expanding a mobile support intervention: Focus group and field-testing findings from individuals in active tuberculosis treatment. Int J Med Inform. 2020;136:104057.

34. Harries AD, Kumar AMV, Satyanarayana S, Thekkur P, Lin Y, Dlodlo RA, et al. The Growing Importance of Tuberculosis Preventive Therapy and How Research and Innovation Can Enhance Its Implementation on the Ground. Trop Med Infect Dis. 2020;5(2).

35. Dorji K, Lestari T, Jamtsho S, Mahendradhata Y. Implementation fidelity of hospital based directly observed therapy for tuberculosis treatment in Bhutan: mixed-method study. BMC Public Health. 2020;20(1):533.

36. de Vries G, Tsolova S, Anderson LF, Gebhard AC, Heldal E, Hollo V, et al. Health system factors influencing management of multidrug-resistant tuberculosis in four European Union countries learning from country experiences. BMC Public Health. 2017;17(1):334.

37. Marme GD. Barriers and facilitators to effective tuberculosis infection control practices in Madang Province, PNG - a qualitative study. Rural Remote Health. 2018;18(3):4401. 
38. Ahmadi A, Nedjat S, Gholami J, Majdzadeh R. Tuberculosis Notification by Private Sector' Physicians in Tehran. Int J Prev Med. 2015;6:129.

39. Dinler G, Sensoy G, Helek D, Kalayci AG. Tuberculous peritonitis in children: report of nine patients and review of the literature. World J Gastroenterol. 2008;14(47):7235-9.

40. Jamaati H, Dastan F, Mirshafiei Langari Z, Haghgoo R, Eskandari R, Marjani M, et al. Study Protocol on Antimicrobial Stewardship in a Tertiary Respiratory Referral Hospital. Tanaffos. 2018;17(3):183-7.

41. Rottenberg ME, Carow B. SOCS3 and STAT3, major controllers of the outcome of infection with Mycobacterium tuberculosis. Semin Immunol. 2014;26(6):518-32.

42. Ferkol T, Schraufnagel D. The global burden of respiratory disease. Ann Am Thorac Soc. 2014;11(3):404-6.

43. Wu K, Koo J, Jiang X, Chen R, Cohen SN, Nathan C. Improved control of tuberculosis and activation of macrophages in mice lacking protein kinase R. PLoS One. 2012;7(2):e30512.

44. Saunders BM, Cooper AM. Restraining mycobacteria: role of granulomas in mycobacterial infections. Immunol Cell Biol. 2000;78(4):334-41.

45. Shin SS, Asencios L, Yagui M, Yale G, Suarez C, Bayona J, et al. Impact of rapid drug susceptibility testing for tuberculosis: program experience in Lima, Peru. Int J Tuberc Lung Dis. 2012;16(11):153843.

46. Dey A, Thekkur P, Ghosh A, Dasgupta T, Bandopadhyay S, Lahiri A, et al. Active Case Finding for Tuberculosis through TOUCH Agents in Selected High TB Burden Wards of Kolkata, India: A Mixed Methods Study on Outcomes and Implementation Challenges. Trop Med Infect Dis. 2019;4(4).

47. Wild V, Frick M, Denholm J. WHO ethics guidance on TB care and migration: challenges to the implementation process. Int J Tuberc Lung Dis. 2020;24(5):32-7.

48. Aye LL, Tripathy JP, Maung Maung T, Oo MM, Nwe ML, Thu HMM, et al. Experiences from the pilot implementation of the Package of Essential Non-communicable Disease Interventions (PEN) in Myanmar, 2017-18: A mixed methods study. PLoS One. 2020;15(2):e0229081.

49. Vo LNQ, Vu TN, Nguyen HT, Truong TT, Khuu CM, Pham PQ, et al. Optimizing community screening for tuberculosis: Spatial analysis of localized case finding from door-to-door screening for TB in an urban district of Ho Chi Minh City, Viet Nam. PLoS One. 2018;13(12):e0209290.

50. Chisompola NK, Streicher EM, Muchemwa CMK, Warren RM, Sampson SL. Molecular epidemiology of drug resistant Mycobacterium tuberculosis in Africa: a systematic review. BMC Infect Dis. 2020;20(1):344.

51. Jacobs J, Hardy L, Semret M, Lunguya O, Phe T, Affolabi D, et al. Diagnostic Bacteriology in District Hospitals in Sub-Saharan Africa: At the Forefront of the Containment of Antimicrobial Resistance. Front Med (Lausanne). 2019;6:205.

\section{Figures}




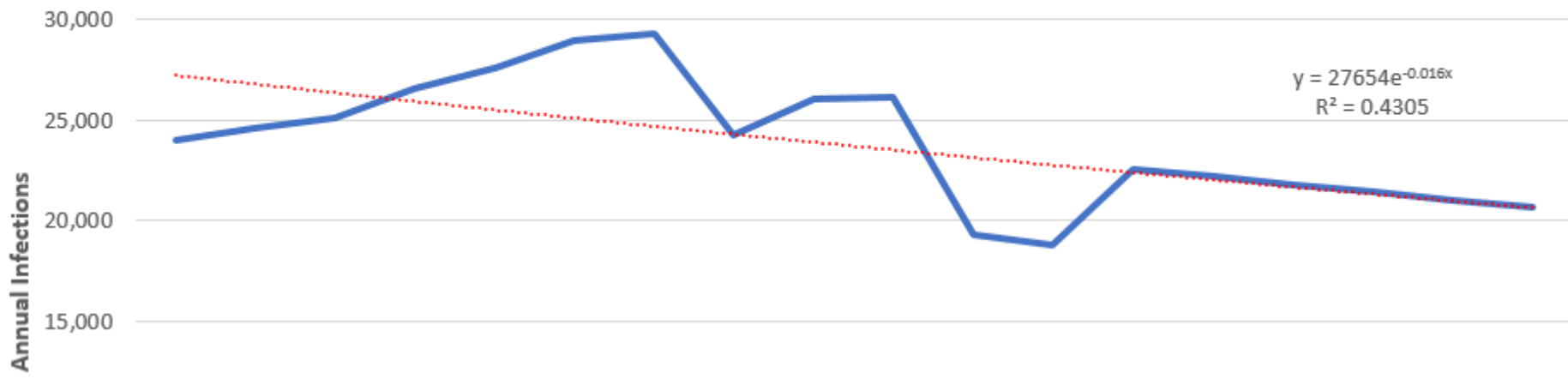

10,000

5,000

0

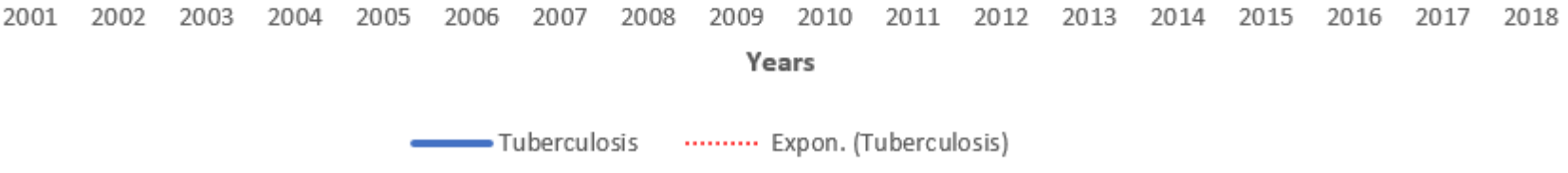

\section{Figure 1}

National tuberculosis infections baseline

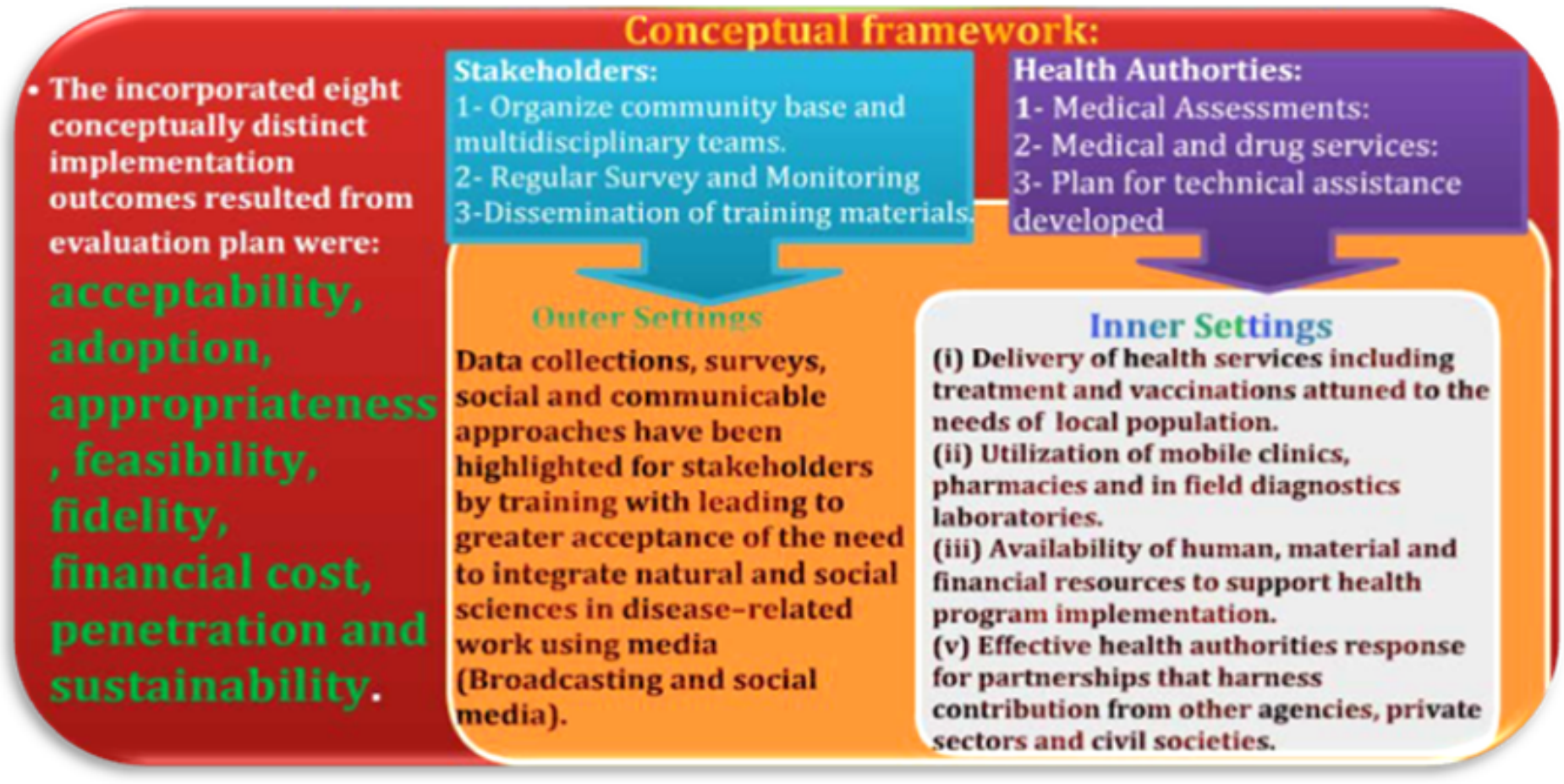

Figure 2 
Innovative strategies for developing tuberculosis framework.

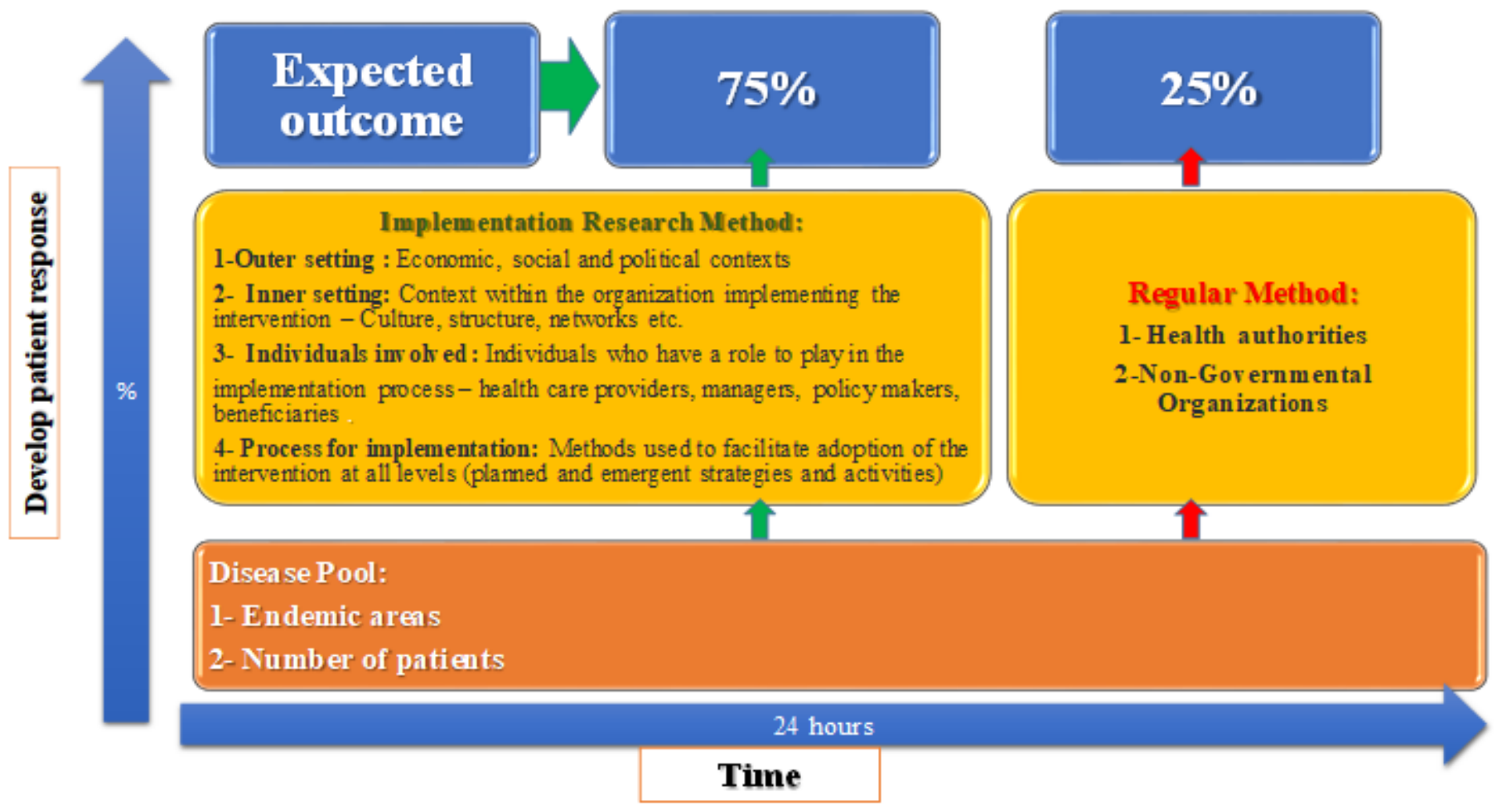

\section{Figure 3}

Conceptual Diagram @Elshayeb 2018

\section{Supplementary Files}

This is a list of supplementary files associated with this preprint. Click to download.

- AppendixA.docx

- AppendixB.docx

- AppendixC.docx

- ApendixD.TIDieRChecklistWord.docx

- TBsamplesizecalculator.xls 